\title{
Reframing active labor market policy: Experimental evidence of training vouchers for unemployed PRE-ANALYSIS PLAN
}

\author{
Lukas Lehner Anna Schwarz
}

February 20, 2021

This document describes the research design and analysis strategy of our field experiment, designed to boost training and employment of unemployed. We start with a detailed outline of the intervention, which takes place in early 2021 during a Covid-19 induced partial lockdown in the region of Lower Austria (Niederösterreich) in Austria. Unemployed receive an email newsletter, which for some contains a training voucher and additional information on job vacancies. We designed multiple different treatment arms to separate out direct effects of raising awareness, supporting reciprocity, and strengthening autonomy. We provide a detailed discussion of our sample selection, variables used and the handling of the data to make the analysis as transparent and replicable as possible. We report the outcomes of our stratified randomization. Further, we state our hypotheses and outcomes of interest motivated by the active labour market policy evaluation literature. Finally, we conclude by specifying our statistical approach to inference.

\section{Background}

\subsection{Description of the intervention}

In February and March 2021, we launch a field experiment designed in cooperation and implemented by the Public Employment Service (PES) of Lower Austria (Arbeitsmarktservice Niederösterreich $(A M S N O \ddot{O})$. The aim is to increase training and employment among the unemployed by increasing participation in and completion of training programs. The intervention consists of an email newsletter that invites unemployed, who have been registered as unemployed for 3 to 12 months, to voluntarily contact the PES to arrange a consultation on training programs. The newsletters will be sent in three waves on February 9th, February 16th, and March 9th. Individuals are assigned to the waves depending on their duration of unemployment.

Context The newsletters are embedded in the broader PES advertisement campaign CoronaJoboffensive to promote participation in training programs amidst the Covid-19 pandemic. In addition to contacting unemployed directly via the newsletter, the PES is establishing a separate hotline for consultations on training opportunities and advertising training opportunities in regional newspapers. Training program participants generally continue to receive their unemployment benefits. Financial incentives to enrolment are provided for training programs with a duration of at least 4 months starting in 2021. They amount to $€ 4$,- per day, which makes around $10-20 \%$ of the benefits received for the median unemployed.

The range of training programs is diverse: from refreshing existing technical knowledge to complete training with an apprenticeship certificate. Common courses include mechatronics, refrigeration 
technology, IT systems technology, programming/coding, plastics technology, as well as training and further education in professions that are in demand, such as restaurant management, hotel and catering assistance or nursing. Also individual training needs are supported, i.e. an unemployed opera singer could receive personal singing classes if this is deemed to increase employment prospects. The duration of the courses varies substantially, depending on the type of course, between several days/weeks up to 18 months for apprenticeship programs. In general, the campaign focuses on longer training programs with a duration starting at around 10 weeks.

Treatments Four different treatment arms vary the type of information provided and the (perceived) autonomy that the unemployed have in choosing a training program. The unemployed in the sample will be randomly allocated to each of the 4 groups on an individual level. This randomization is conducted separately for each sending date, which ensures that unemployed with different unemployment durations are equally divided within the groups. Further information about the randomization procedure is provided in section 2.4

The different treatment arms are as follows:

1. Group: control

2. Group: treatment with newsletter (Figure 3)

3. Group: treatment with newsletter, and voucher (Figure 4 Figure 2)

4. Group: treatment with newsletter, voucher, and information prime (Figure 5 , Figure 2)

Group 1 functions as the control group and is not contacted at all.

Group 2 receives a newsletter (Figure 3 that includes an invitation to a consultation to discuss potential training programs with the PES' job counselor and provides information about existing financial incentives to start a training program.

In addition, groups 3 and 4 receive a voucher (Figure 2 worth $€ 15.000,-$, which can be redeemed to take part in training programs provided by the PES. Alternatively, the voucher can be redeemed in consultation with the PES for any outside training for up to $€ 3.000,-[$ The groups receiving the voucher further obtain a list of typical training programs as part of the newsletter (Figure 4 ). This should motivate the unemployed in these two groups to already think about their preferred training program before the consultation at the PES. Finally, job counselors are instructed to take serious the voucher received by unemployed. The treatment is designed to increase self-initiative for the unemployed and raise awareness for the financial value of such training programs, thus inducing reciprocity.

Finally, group 4 receives in addition to the voucher an information treatment consisting of a list of occupations with the highest number of job vacancies (Figure 5). This information treatment is intended to counteract a frequently mentioned concern related to asymmetric information in the use of training vouchers: unemployed allegedly do not have enough information to make an informed choice about their optimal training program (Strittmatter, 2016). It will additionally increase (perceived) autonomy as it encourages even more to think about potential course choices before the consultation at the PES.

In general, all groups (including the control group) have access to the same training programs, both provided by the PES as well as outside training. The intervention, thus, consists of the variation in the type of information provided. Additionally, it varies the actual and perceived autonomy that the unemployed have in choosing their courses.

\footnotetext{
${ }^{1}$ The PES generally provides funding of up to $€ 3.000$,- for training programs of external suppliers, including for groups 1 and 2. However, this is not advertised and therefore awareness wil be limited for group 1 and 2.
} 
Conditionality Currently, by law (Arbeitslosenversicherungsgesetz (AlVG §9)), unemployed are assigned to labor market programs by the PES. This takes place after a consultation with the job counselor. In most cases, consultations with the job counselors and program assginment is obligatory, i.e. with conditionality attached. If an unemployed does not attend a PES appointment or assigned program - typically with no shows - the unemployment benefits can be cut or - in the most severe cases - blocked temporarily. Absences with a valid excuse, such as for sick leave, are exempted. As a result, assignment to a training program is often perceived negatively as a burden or punishment rather than positively as an opportunity and support.

In general, job consultations are obligatory for unemployed and often imply limited discussion with unemployed about their preferences. In the context of our experiment, the consultation with the job counselor is open to all treatment and control groups. Attendance is voluntary and only takes place if an unemployed contacts the PES on her own initiative, i.e. as a response to the newsletter. By law, job counselors are required to assess the adequacy of any training program and approve of it (Arbeitsmarktpolitische Prüfung). Job counselors approve suggestions for training programs as long as they credibly contribute to increasing the employment prospects of the unemployed. Course choice that seem purely for personal pleasure are declined. The time span between selection and start of the course will be held as short as possible; usually well below 3 months.

\subsection{Timeline for the intervention}

The intervention takes place in three waves in February and March 2021:

- Wave 1, February 9: unemployed with a spell of 6 to 9 months (181-270 days)

- Wave 2, February 16: unemployed with a spell of 9 to 12 months (271-365 days)

- Wave 3, February 23: unemployed with a spell of 3 to 4 months who did not receive the newsletter previously due to a too short spell 2

First analyses of short-term treatment effects are intended to be carried out with outcome data provided by the PES in several rounds in 2021. Longer-term effects are intended to be estimated with data provided by the PES each year until 2026. This will allow us to estimate long-term effects up to at least 5 years after the intervention.

\subsection{Covid-19 impact}

Saftey measures The PES takes specific measures to protect the health of training program participants during the pandemic. Parts of the training move to online teaching but personal presence is allowed where necessary. Wearing FFP2 masks and the distance rule of two metres is obligatory for on-site training. If required, laptops are offered to enable virutal training from home.

Labor market crisis The timing of the intervention is amidst the Covid-19 crisis, which affected the Austrian labor market severely. In December 2020 the absolute number of unemployed persons in Austria has reached nearly 500.000 people, which is around 30\% higher than in December 2019 (AMS-Uebersichtsbericht, 2021). The situation in Niederösterreich, the region we study, is slightly better with around 70.000 unemployed and an increase of $18 \%$ in comparison to the previous year (AMS-Uebersichtsbericht, 2021). The most affected subgroups were young and blue collar workers. The impact is very uneven across sectors with tourism, hospitality and personal services hit hardest by a drop in employment due to government induced shutdowns (Bock-Schappelwein, Huemer, and Hyll, 2021).

\footnotetext{
${ }^{2}$ All unemployed with a spell of 3 to 6 months (91-180 days) received the standard newsletter on February 2. They are not included in the experimental design since all received the same treatment.
} 
Lock-in effects When considering the literature about the effects of training programs for the unemployed the presence of so-called lock-in effects is undisputed. Training programs, thus, first lead to negative employment effects, as they take up a considerable amount of time for the unemployed, which reduces time spent on job search or even prevents take-up of available jobs (Vooren et al., 2019). Positive employment effects were found to materialize only in the long-term, i.e. at the earliest one year afterwards. However, these lock-in effects are strongly dependent on the current labor market situation. In times of high unemployment and dense labor markets, these lock-in effects are reduced, which, in turn, increases the effectiveness of training programs in recessions (Card, Kluve, and Weber, 2018). In light of this evidence, the timing of the intervention was deliberately set amidst the Covid-19 crisis to maximize it's effectiveness.

\section{Study design}

\subsection{Overview}

In this section, we describe our analytical approach in detail. Firstly, we specify the criteria for inclusion in our sample and related limitations. Secondly, we describe the data. Thirdly, we present the randomisation procedure for our treatment assignment. Fourthly, we state our hypotheses regarding outcomes. Fifthly, we specify the details of our outcome variables. Finally, we discuss our estimation and inference approach.

The code implementing the following designs has been uploaded to GitHub, at https://github. com/lukaslehner/Vouchers. For the stratified randomization, we use the package randomizr in $R$.

\subsection{Sample selection}

Our sample comprises of around 11.000 unemployed. They are distributed over 3 waves with 3.700 people in wave $1,4.615$ in wave 2 , and 2.690 in wave 3 . This makes up for around $20 \%$ of all currently unemployed in Lower Austria. Sample selection for waves 1 and 2 follows the criteria of every person, who has been registered as unemployed with the PES for 6 to 12 months. Additionally, with the last wave, we also capture those, who have been unemployed at the start of the intervention for between 2 and 3 months.

Individuals with the status "unemployed" as well as "in job search" are included, meaning that all registered unemployed are included regardless of whether they receive unemployment benefits or not. Unemployed who are already enrolled in a training program in Schulung at the time of the intervention are excluded from the sample. The sample is further restricted to people, who are at least 25 years old and do not have a pending job acceptance.

Since the newsletter is sent via email only registered unemployed with a valid email can be contacted. Unemployed without a valid email are not included in the randomisation procedure and thus excluded from the study. This applies to around $25 \%$ of the population.

Finally, as mentioned above, the context amidst the Corona crisis is very specific. The number of unemployed people is much higher, which also influences the characteristics of the unemployed that are clearly different in recessions than during normal economic conditions. Our findings are thus very well suited to infer the effectiveness of such an intervention during a recession, but the generalizability to normal economic conditions or a boom is therefore limited. We will, however, describe how our sample of unemployed differs from the unemployed before the Covid-crisis. Additionally, a subset of our sample has been unemployed already before the Covid-crisis, which we will exploit in the heterogeneity analysis. Nevertheless, the special economic conditions will influence the effectiveness of the intervention also through other channels than the characteristics of the unemployed, such as the already mentioned lock-in effects or the number and type of job openings 
after the training is completed etc.

These aspects have to be kept in mind when generalizing our results to a broader population of unemployed or to different economic conditions.

\subsection{Data}

Administrative data All data used in the analysis is provided by the PES and consists of administrative data. No additional data will be collected. Table 1 shows a summary and categorisation of all variables used.

Table 1: Variables

\begin{tabular}{ll}
\hline Type & Variable name \\
\hline Primary outcomes & Training completion \\
& Labor market status ${ }^{1}$ \\
& Job quality (Indicator including earnings and employment stability) \\
\hline Secondary outcomes & Newsletter read + Clicks \\
& Training take-up \\
& Type of training \\
\hline Stratified Randomization & Education (binary: compulsory school, higher) \\
& Unemployment duration (following the 3 waves) \\
& Age (below 35 years, 35-50 years, above 50 years) \\
& Gender (binary: men, women) \\
& Region (Weinviertel, Mostviertel, Waldviertel, Industrieviertel) \\
\hline Control Variables & Strata \\
& relevant variables not included in stratification: \\
& job counselor, income level, experience, sector \\
& medical condition, nationality, language proficiency \\
& occupation (ISCO-08 1-digit), marginal employment \\
& Education \\
& Unemployment duration \\
& Pre- and In-Corona unemployed ${ }^{3,4}$ \\
& Income level ${ }^{2,3}$ \\
& Age \\
\hline Heterogeneity analysis & Gender \\
\hline March 2020 & \\
\hline 1 differentiated by employment and labor force exit. & \\
&
\end{tabular}

Attrition \& Exclusions We will make an effort to keep attrition to a minimum. As we use solely administrative data, we expect attrition to be negligibly low. It is, however, possible that participants move abroad or pass away. We will test, whether those who attrit are systematically different from the rest of the sample and report the results. Further, we can provide estimates 
of lower and upper bounds of our estimated effects depending on different assumptions we make about the part of our sample, that shows attrition.

Firstly, as mentioned above, all unemployed who do not have a valid email are excluded from the study by definition, as we cannot reach them. However, we have data about this subsample and can check whether they differ systematically from our sample and discuss potential biases. Additionally, those who are already taking part in a training program are also not included in our sample, because they are, in some way, already treated. It would not make any sense to treat them with our intervention, as they cannot enrol in another training program in parallel. Our findings thus extend only to those unemployed who are not already in training programs and should be generalized to the entire population of unemployed only with caution.

\subsection{Treatment assignment}

The randomization is conducted for every wave separately, thus practically stratifying by the three categories of unemployment duration dividing the three waves. In addition, we use the other stratification variables as specified in table 1 to construct strata, i.e. blocks. The treatment assignment is in a next step conducted randomly within these strata. Ideally, we would like to stratify by more variables than just the five used, but the sample size does not allow more stratification variables, because then the strata would become too small.

In total, we constructed 145 strata for every possible combination of the values of the 5 strata variables. The minimum number of observations per strata is 10 , while the maximum is 270 , as can be seen in figure 1 .

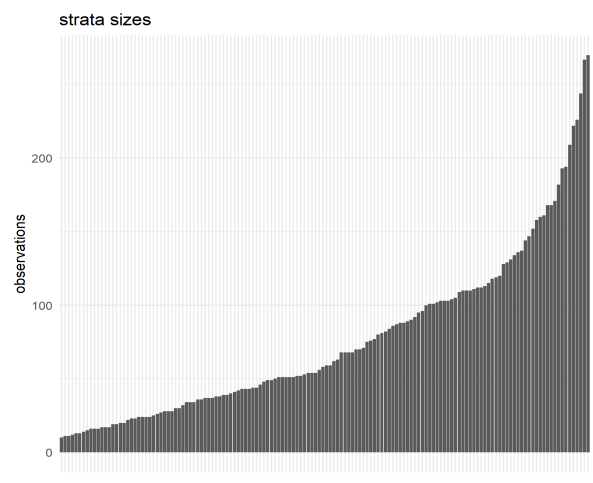

Figure 1: Strata size

However, it has to be mentioned that we had 36 observations with missing education and 7 with missing nationality, which we assigned completely randomly to the 4 groups. Further, in table 2 the distribution of covariates between the control group and the 3 treatment groups is shown. The p-value refers to the p-value of a Chi-squared test, which tests the Null-hypothesis that there are no differences between the 4 groups. We see that the p-values are large for all groups, even for those, where no stratification has been performed. 


\begin{tabular}{|c|c|c|c|c|c|c|}
\hline & $\mathrm{T} 1(\mathrm{~N}=2769)$ & $\mathrm{T} 2(\mathrm{~N}=2766)$ & T3 $(\mathrm{N}=2760)$ & $\mathrm{T} 4(\mathrm{~N}=2755)$ & Total $(\mathrm{N}=11.050)$ & $\mathrm{p}$ value \\
\hline Gender & & & & & & 0.999 \\
\hline women & $1437(51.9 \%)$ & $1434(51.8 \%)$ & $1433(51.9 \%)$ & $1434(52.1 \%)$ & $5738(51.9 \%)$ & \\
\hline men & $1332(48.1 \%)$ & $1332(48.2 \%)$ & $1327(48.1 \%)$ & $1321(47.9 \%)$ & $5312(48.1 \%)$ & \\
\hline Age group & & & & & & 1.000 \\
\hline Below 35 years & $831(30.0 \%)$ & $828(29.9 \%)$ & $826(29.9 \%)$ & $823(29.9 \%)$ & $3308(29.9 \%)$ & \\
\hline 35 - 50 years & $1062(38.4 \%)$ & $1067(38.6 \%)$ & $1064(38.6 \%)$ & $1063(38.6 \%)$ & $4256(38.5 \%)$ & \\
\hline over 50 years & $876(31.6 \%)$ & $871(31.5 \%)$ & $870(31.5 \%)$ & $869(31.5 \%)$ & $3486(31.5 \%)$ & \\
\hline Education & & & & & & 1.000 \\
\hline Missing & 10 & 9 & 8 & 9 & 36 & \\
\hline Primary & $897(32.5 \%)$ & $898(32.6 \%)$ & $896(32.6 \%)$ & $891(32.4 \%)$ & $3582(32.5 \%)$ & \\
\hline Higher than primary & $1862(67.5 \%)$ & $1859(67.4 \%)$ & $1856(67.4 \%)$ & $1855(67.6 \%)$ & $7432(67.5 \%)$ & \\
\hline Region & & & & & & 1.000 \\
\hline Industrieviertel & $1222(44.1 \%)$ & $1225(44.3 \%)$ & $1227(44.5 \%)$ & $1219(44.2 \%)$ & $4893(44.3 \%)$ & \\
\hline Mostviertel & $741(26.8 \%)$ & $731(26.4 \%)$ & $732(26.5 \%)$ & $732(26.6 \%)$ & $2936(26.6 \%)$ & \\
\hline Waldviertel & $243(8.8 \%)$ & $245(8.9 \%)$ & $239(8.7 \%)$ & $241(8.7 \%)$ & $968(8.8 \%)$ & \\
\hline Weinviertel & $563(20.3 \%)$ & $565(20.4 \%)$ & $562(20.4 \%)$ & $563(20.4 \%)$ & $2253(20.4 \%)$ & \\
\hline Unemp. dur. & & & & & & 1.000 \\
\hline 3 - 4 Months & $676(24.4 \%)$ & $675(24.4 \%)$ & $671(24.3 \%)$ & $668(24.2 \%)$ & $2690(24.3 \%)$ & \\
\hline 6 - 9 Months & $937(33.8 \%)$ & $937(33.9 \%)$ & $937(33.9 \%)$ & $934(33.9 \%)$ & $3745(33.9 \%)$ & \\
\hline 9 - 12 Months & $1156(41.7 \%)$ & $1154(41.7 \%)$ & $1152(41.7 \%)$ & $1153(41.9 \%)$ & $4615(41.8 \%)$ & \\
\hline Nationality & & & & & & 0.778 \\
\hline Missing & 1 & 2 & 3 & 1 & 7 & \\
\hline Austria & $2147(77.6 \%)$ & $2146(77.6 \%)$ & $2150(78.0 \%)$ & $2165(78.6 \%)$ & $8608(77.9 \%)$ & \\
\hline other & $621(22.4 \%)$ & $618(22.4 \%)$ & $607(22.0 \%)$ & $589(21.4 \%)$ & $2435(22.1 \%)$ & \\
\hline Health & & & & & & 0.991 \\
\hline No health restriction & $2185(78.9 \%)$ & $2177(78.7 \%)$ & $2168(78.6 \%)$ & $2169(78.7 \%)$ & $8699(78.7 \%)$ & \\
\hline Health restriction & $584(21.1 \%)$ & $589(21.3 \%)$ & $592(21.4 \%)$ & $586(21.3 \%)$ & $2351(21.3 \%)$ & \\
\hline Marg. empl. & & & & & & 0.733 \\
\hline No & $2457(88.7 \%)$ & $2479(89.6 \%)$ & 2467 (89.4\%) & $2463(89.4 \%)$ & $9866(89.3 \%)$ & \\
\hline Yes & $312(11.3 \%)$ & $287(10.4 \%)$ & $293(10.6 \%)$ & $292(10.6 \%)$ & $1184(10.7 \%)$ & \\
\hline German & & & & & & 0.456 \\
\hline Partial or non & $404(14.6 \%)$ & $403(14.6 \%)$ & $377(13.7 \%)$ & $418(15.2 \%)$ & $1602(14.5 \%)$ & \\
\hline Proficient or native & $2365(85.4 \%)$ & $2363(85.4 \%)$ & $2383(86.3 \%)$ & $2337(84.8 \%)$ & $9448(85.5 \%)$ & \\
\hline
\end{tabular}

Table 2: Covariate Balance Chi-squared test

We further conducted pairwise z-tests to test for differences in covariates between each of the groups separately, which can be seen in table 3 . Any significant differences would be shown by a letter indicating the group to which the z-test indicated a difference. Again, we can never reject the null hypothesis that there is no difference in the covariates between each of the groups, even when compared pairwise. 


\begin{tabular}{lllll}
\hline & $\mathrm{T} 1(\mathrm{~N}=2769)$ & $\mathrm{T} 2(\mathrm{~N}=2766)$ & $\mathrm{T} 3(\mathrm{~N}=2760)$ & $\mathrm{T} 4(\mathrm{~N}=2755)$ \\
& $\mathrm{A}$ & $\mathrm{B}$ & $\mathrm{C}$ & $\mathrm{D}$ \\
\hline Women & 51.9 & 51.8 & 51.9 & 52.1 \\
Men & 48.1 & 48.2 & 48.1 & 47.9 \\
Below 35 years & 30.0 & 29.9 & 29.9 & 29.9 \\
35-50 years & 38.4 & 38.6 & 38.6 & 38.6 \\
Above 50 years & 31.6 & 31.5 & 31.5 & 31.5 \\
Primary education & 32.5 & 32.6 & 32.6 & 32.4 \\
Higher than primary & 67.5 & 67.4 & 67.4 & 67.6 \\
& & & & \\
Industriesv. & 44.1 & 44.3 & 44.5 & 44.2 \\
Mostv. & 26.8 & 26.4 & 26.5 & 26.6 \\
Waldv. & 8.8 & 8.9 & 8.7 & 8.7 \\
Weinv. & 20.3 & 20.4 & 20.4 & 20.4 \\
& & & & \\
2-4 Months unemp. & 24.4 & 24.4 & 24.3 & 24.2 \\
6-9 Months unemp. & 33.8 & 33.9 & 33.9 & 33.9 \\
9-12 Months unemp. & 41.7 & 41.7 & 41.7 & 41.9 \\
Other nationality & 22.4 & 22.4 & 22.0 & 21.4 \\
Austrian & 77.6 & 77.6 & 78.0 & 78.6 \\
No health restriction & 78.9 & 78.7 & 78.6 & 78.7 \\
Health restriction & 21.1 & 21.3 & 21.4 & 21.3 \\
No marg. empl. & 88.7 & 89.6 & 89.4 & 89.4 \\
Marg. empl. & 11.3 & 10.4 & 10.6 & 10.6 \\
Partial or no German & 14.6 & 14.6 & 13.7 & 15.2 \\
Proficient or native German & 85.4 & 85.4 & 86.3 & 84.8 \\
\hline & & & & \\
\hline
\end{tabular}

Table 3: Covariate Balance, pairwise z-tests

In appendix B we report the treatment assignment procedure and the balance checks for every wave separately. We do not find any problematic differences between the groups in each separate wave.

\subsection{Hypotheses}

We have several hypotheses regarding the different treatment groups and different outcome variables:

1. Group 2-4 will achieve higher training program take-up and completion rates than the control group, but groups 3 and 4 will have even higher take-up and completion rates than group 2.

2. We expect negative short-term effects (due to the so-called lock-in effects) on unemployment duration for group 2-4, which however will turn positive for all treatment groups in the long-term.

3. Further, re-employment rates will be highest in group 4, followed by group 3, 2, and lastly the control group. 
4. Finally, job quality will follow the same pattern as re-employment rates, but probably less pronounced.

Training program take-up and completion rate The first hypothesis follows from studies, such as Doerr and Strittmatter (2018). They show that motivation to take-up and complete courses increases with voucher systems, due to increased autonomy, reciprocity and higher valuation of financial costs of such programs. In turn, voucher systems lead to less drop-out from courses. Finally, group 2 is expected to exhibit higher training program take-up rates than the control group, because they are informed about the positive effects of training and therefore nudged towards training program participation.

Unemployment duration As described above, negative short-term effects on unemployment duration are relatively well-established in the literature and we therefore expect them as well in our setting; however smaller in size due to limited job vaccancies as a result of the Covid-19 crisis. Further, these negative short-term effects turn into positive long-term effects on unemployment duration, as shown the literature about effects of training for the unemployed with and without vouchers (Card, Kluve, and Weber, 2018, Doerr and Strittmatter, 2018).

Re-employment rates The third hypothesis follows directly from the variation in training participation between the groups. In addition, group 4 is expected to have higher re-employment rates because of the additional labour market information received. This information treatment is expected to counter the problem of asymmetric information with training vouchers, well established in the literature (Perez-Johnson, Moore, Santillano, et al., 2011 Strittmatter, 2016), and could therefore lead to better targeted training choices.

Job Quality The indicator for job quality, described in more detail below, consists of information about earnings in the job after the unemployment spell and the stability of employment. Earnings should follow the same pattern as re-employment rates due to the variation in training participation and the additional information in group 4. However, the effects on earnings are often less pronounced and clear-cut than those on re-employment (Card, Kluve, and Weber, 2018). There is not much evidence for the effect on employment stability, but we expect it to follow the same pattern as earnings.

\subsection{Outcomes of interest}

All data on outcomes of interest are available from administrative data sources, provided by the PES.

Primary outcomes Our three primary outcomes are training completion, labor market status, and job quality. The first one refers to whether or not a course/training program is completed. The second one differentiates between: unemployed, employed, out-of-labor force. We can, thus, differentiate between people exiting unemployment because they found a job and those exiting unemployment, because they dropped out of the labor force. This differentiation is important for drawing conclusions from the findings. Finally, job quality is important, which we proxy by combining earnings and employment stability into an indicator. Employment stability is defined via the duration of the employment spell after unemployment, independent of the specific job. This means, job-to-job transitions still count as employment, but job-to-unemployment transitions do not. We first normalize both variables and then combine them with equal weight to construct the job quality indicator. However, job quality is only observed for those who actually found a job. Therefore, we provide estimates for effects on job quality conditional on finding a job, but also for 
effects on the probability of having an above-average job quality indicator. The latter can account for this inherent endogeneity (Rothstein and Von Wachter, 2017).

Secondary outcomes The following secondary outcomes are not per se desired outcomes, but can be seen as mechanisms leading to the primary outcomes described above. In this context we will look at whether or not the email was read, newsletter clicks, and course take-up. We will differentiate by the type of course to check whether the intervention also changes training choices.

\subsection{Estimation and inference}

Due to the clean randomization of participants into control and treatment groups it is possible to, in a first step, compare the relevant outcome variables directly between the 4 groups via a twosided test, such as a T-test or Mann-Whitney test or others, which will be chosen depending on the distribution of the outcome variables (Moffatt, 2019). This randomization inference will provide us with an unbiased estimate of the treatment effect that does not hinge on any assumptions other than the random assignment into the groups. Throughout the whole study, we will infer statistical significance via a p-value of 0.05 or below, thus using a $95 \%$ confidence interval.

To increase precision and test robustness we will additionally estimate parametric regressions for the treatment effects using the following estimation regression:

$$
Y_{i}=\beta_{0}+\beta_{1} T_{N L}+\beta_{2} T_{V}+\beta_{3} T_{V+I}+\mathbf{X}_{\mathbf{i}}+\epsilon_{i}
$$

where $Y_{i}$ refers to the interesting outcome variables for individual i. Depending on the scale of the outcome variable, an OLS(continuous) or a Logit(binary) regression is used. Our outcome variables are measured at different time periods and for each time period a separate regression is estimated to measure time-varying treatment effects. In the baseline specification the control group is the reference group, but depending on which difference between groups has to be estimated, the reference group will be chosen accordingly. $T_{N L}$ is the second group with only the newsletter, $T_{V}$ is the third group with the voucher, and $T_{V+I}$ is the fourth group with voucher and information prime. Additionally, we will estimate the effect of just receiving an email by combining all treatment group dummies into one in equation 1. Further, we include all control variables specified in table 1 and measured before treatment, which is represented by $\mathbf{X}_{\mathbf{i}}$ in the specification above. Finally, standard errors will be adjusted to be robust to heteroskedasticity, if necessary. The regression will be estimated such that stratification is taken into account when computing the variance and standard errors of the estimates, following Athey and Imbens (2017). Finally, the specified regression can also be estimated conditional on reading the email, which allows us to estimate the average treatment effect on the treated as opposed to the intention-to-treat effect described above. This estimate refers to the effect of the intervention for those, who actually open the email, which reduces noise from the specification introduced by those, who do not receive the intervention, because they do not open the email. However, those who open the email may differ systematically from those who do not open the email, which has to be kept in mind when interpreting these treatment effects on the treated.

Heterogeneity analysis The heterogeneity analysis will be conducted via subgroup regressions of the equation above for the variables specified in table 1 . Additionally, the treatment dummies in the equation above can be interacted with the pre-specified variables in table 1 and estimated for the relevant heterogeneity variables separately. 
Multiple outcomes adjustment To control the false discovery rate in conjunction with multiple hypotheses testing we will take two approaches. First, for the treatment effects on the primary outcome variables, we will report the mean standardized treatment effect with it's standard error adjusted for the dependency between the different outcome variables, following Duflo, Glennerster, and Kremer (2007). Further, we will use the Benjamini-Hochberg procedure (Romano, Shaikh, and Wolf, 2010) for the primary outcomes as well as the heterogeneity analysis, which works as follows. Sort the p-values, for each of the $m$ hypotheses, tested by size, resulting in ordered values $P_{(j)}$. For a critical value $\alpha$, find the largest value $k$ such that

$$
P_{(k)} \leq \frac{k}{m} \alpha .
$$

Reject the null hypothesis for all $i=1, \ldots, k$.

\section{Publication agreement}

This evaluation is based on an agreement between the researchers (i.e. Lukas Lehner and Anna Schwarz) and the AMS NÖ. Two key components of this agreement are that (1) no payment will be made from the $A M S N O ̈$ to the researchers, and (2) the researchers are guaranteed to be entitled to publish the findings of their study in academic outlets without any interference by the $A M S$ $N O ̈$. The $A M S N O ̈$ may publish the results of the study in mass media as well as the AMS research network at any time.

\section{References}

AMS-Uebersichtsbericht (2021). Uebersicht ueber den Arbeitsmarkt - Dezember 2020. Tech. rep. AMS-Arbeitsmarktservice Österreich.

Athey, Susan and Guido W Imbens (2017). "The econometrics of randomized experiments". In: Handbook of economic field experiments. Vol. 1. Elsevier, pp. 73-140.

Bock-Schappelwein, Julia, Ulrike Huemer, and Walter Hyll (2021). Beschaeftigung 2020: Bilanz nach einem Jahr COVID-19-Pandemie. Tech. rep. WIFO Research Briefs 1/2021.

Card, David, Jochen Kluve, and Andrea Weber (2018). "What works? A meta analysis of recent active labor market program evaluations". In: Journal of the European Economic Association 16.3 , pp. 894-931.

Doerr, Annabelle and Anthony Strittmatter (2018). "Do vouchers impact the effectiveness of training programmes? The disentangling of causal channels". In.

Duflo, Esther, Rachel Glennerster, and Michael Kremer (2007). "Using randomization in development economics research: A toolkit". In: Handbook of development economics 4, pp. 38953962.

Moffatt, Peter G (2019). "Data analysis". In: Handbook of Research Methods and Applications in Experimental Economics. Edward Elgar Publishing, pp. 57-82.

Perez-Johnson, Irma L, Quinn Moore, Robert Santillano, et al. (2011). Improving the effectiveness of individual training accounts: Long-term findings from an experimental evaluation of three service delivery models. US Department of Labor, Employment and Training Administration.

Romano, Joseph P, Azeem M Shaikh, and Michael Wolf (2010). "Hypothesis testing in econometrics". In: Annu. Rev. Econ. 2.1, pp. 75-104.

Rothstein, Jesse and Till Von Wachter (2017). "Social experiments in the labor market". In: Handbook of Economic Field Experiments. Vol. 2. Elsevier, pp. 555-637.

Strittmatter, Anthony (2016). "What effect do vocational training vouchers have on the unemployed?" In: IZA World of Labor. 
Vooren, Melvin et al. (2019). "The effectiveness of active labor market policies: a meta-analysis". In: Journal of Economic Surveys 33.1, pp. 125-149.

\section{A Appendix: Treatment}

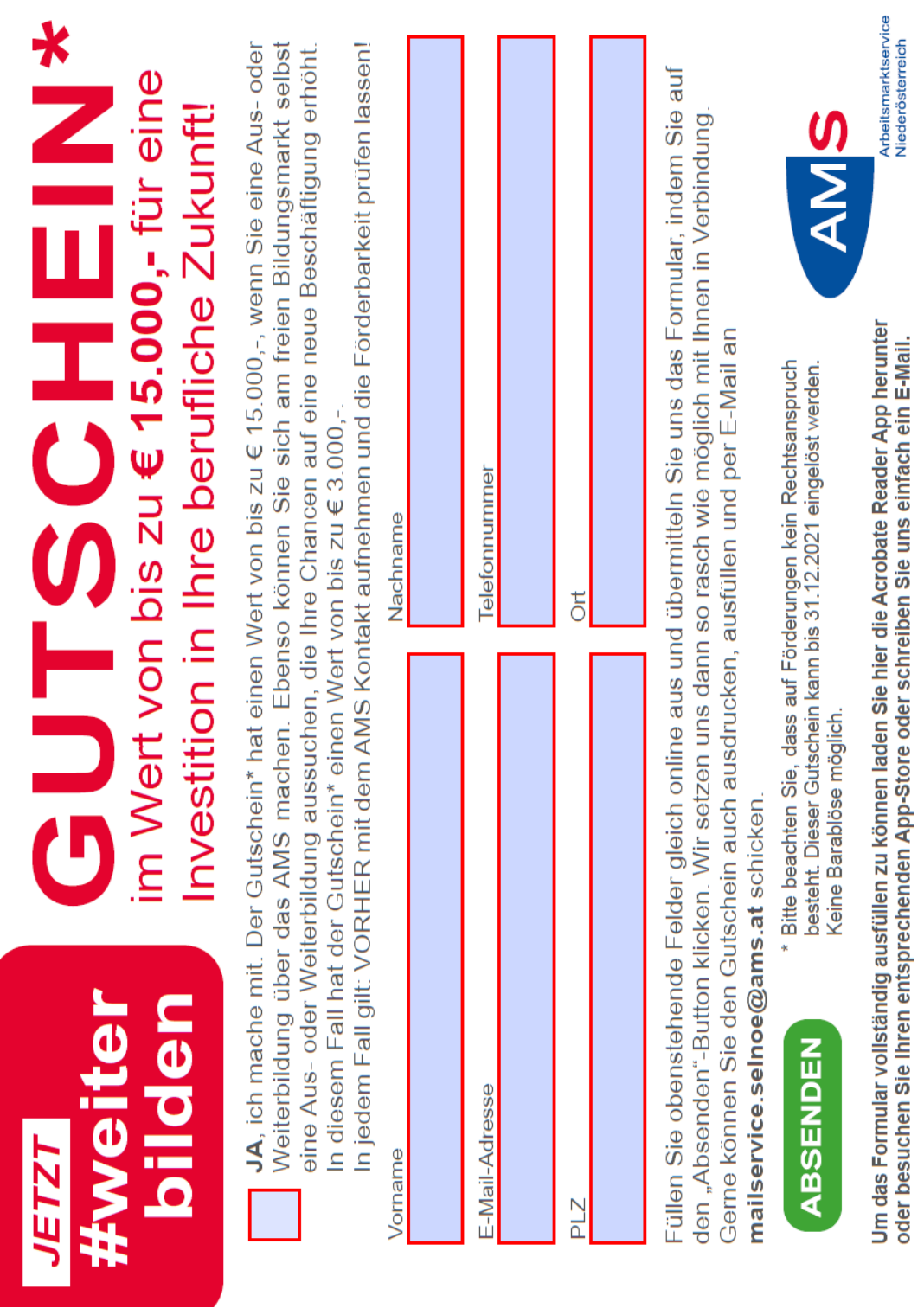

Figure 2: Voucher for groups 3 and 4 
$09 / 02 / 2021$

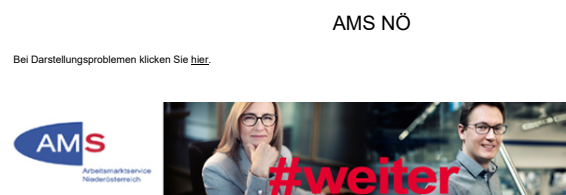

Thr Weg zum beruffichen Neustart

Sehr geehrte Damen und Herren,

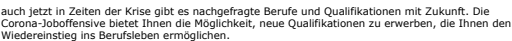

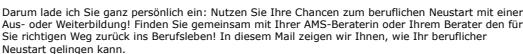

Sie richtigen weg auruch
Neustart gelingen kann.

Nehmen Sie Ihre beruffiche Zukunft in die Hand - und bleiben Sie gesund!

Sven Hergovich
Landesgeschăftsounrer des AMS Niederósterreich

Aus- und Weiterbildung für den Neustart am Arbeitsmarkt

Aktuelle und nachgefragte Qualifikationen sind der wichtigste Erfolgsfaktor für den beruffichen
Neustart.

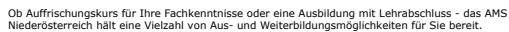

Einige Beispiele:

- Metall- und elektrotechnische Berufe

Mechatroni

- Beruffkraftfahrer/in, Transportwesen

Weiterbifildungsangabebol
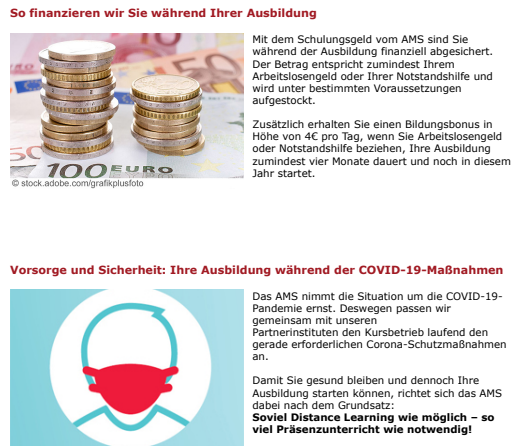

Informieren Sie sich jetzt!

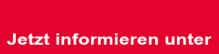

050904343

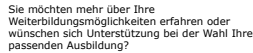

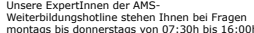

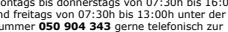

verúgunga.

Oder Sie schreiben ein E-Mail.

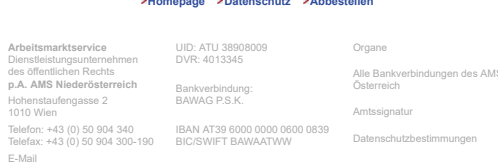

www.emarsys.net/archive.php?p=127377193_1593456

Figure 3: Newsletter for group 2 
$09 / 02 / 2021$

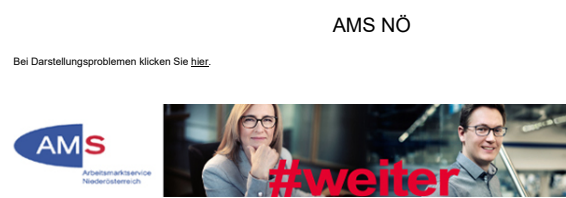

Ihr Weiterbildungsgutschein im Wert von bis zu 15.000,- Euro

Sehr geehrte Damen und Herren,

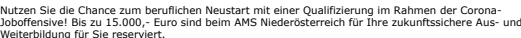

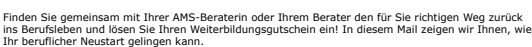

Nehmen Sie Ihre beruffiche Zukunft in die Hand - und bleiben Sie gesund!

Sven Hergovich
Landesgeschafftsürer des AMS Niederossterreich

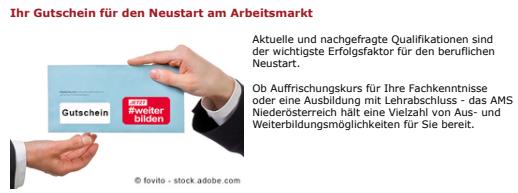

Eine Auswahl der Berufsausbildungen, für die das AMS die Kosten übernimmt:

- Mechatronic

- Kälteanlagentechnik

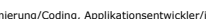

- Kunstofftechnik

- Berufskratffahrer/in

- Diplomlehrgang Digitaler Vertrieb

Thr Weiterbildungsgutschein im Wert von bis zu C 15.000,
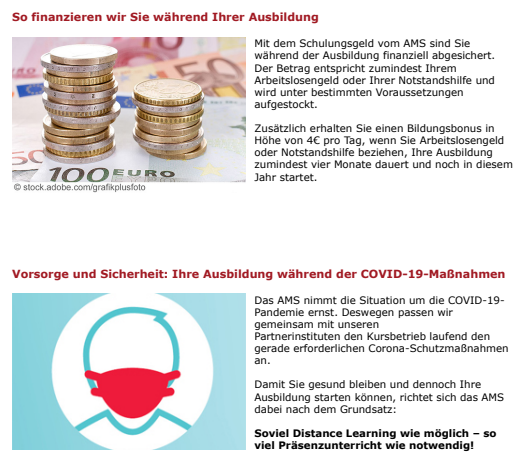

Informieren Sie sich jetzt!

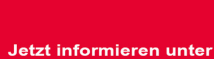

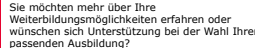

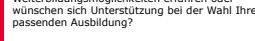

Unsere Expertlnnen der AMS-
Wetterbildungshotline

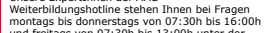

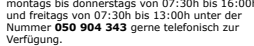

050904343

Oder Sle schreiben uns ein E-Mail.

Figure 4: Newsletter for group 3 

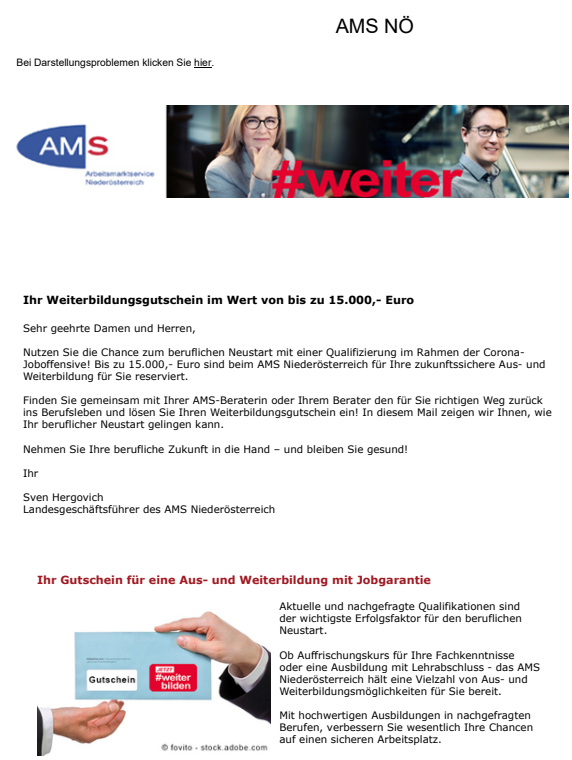

Eine Auswahl der Berufsausbilldungen, für die das AMS die Kosten übernimmt:

- Mechatronik

- Kälteanlagentechnik

(a)

- Kunstofftechnik

- Berufskrafteahrer/in

- Finanz- und Rechnungswesenassistenz

- Diplomlehrgang Digitaler Vertrieb

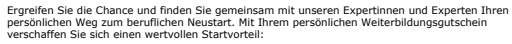

Ihr Weiterbildungsgutschein im Wert von bis zu C 15.000,
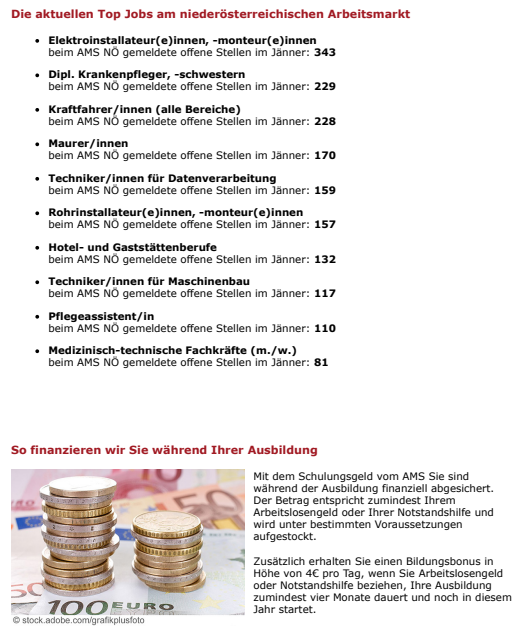

Vorsorge und Sicherheit: Ihre Ausbildung während der CoviD-19-Maßnahmen

Figure 5: Newsletter for group 4 


\section{B Appendix: Treatment Assignment}

First Wave For the first wave, the result of the randomization is as follows. 48 strata were constructed, with a minimum of 10 observations and a maximum of 226 , as can be seen in figure 6.

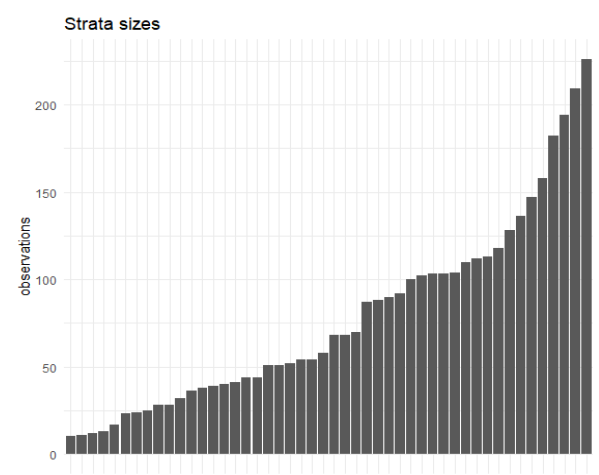

Figure 6: Strata size in Wave 1

However, it has to be mentioned that we had 7 observations with missing education and 5 with missing nationality, which we assigned completely random to the 4 groups. Further, in table 4 the distribution of covariates between the control group and the 3 treatment groups is shown. The p-value refers to the p-value of a Chi-squared test, which tests the Null-hypothesis that there are no differences between the 4 groups. We see that the p-values are large for all groups, even for those, where no stratification has been performed. 


\begin{tabular}{|c|c|c|c|c|c|c|}
\hline & $\mathrm{T} 1(\mathrm{~N}=937)$ & $\mathrm{T} 2(\mathrm{~N}=937)$ & T3 $(\mathrm{N}=937)$ & $\mathrm{T} 4(\mathrm{~N}=934)$ & Total $(\mathrm{N}=3745)$ & $\mathrm{p}$ value \\
\hline Gender & & & & & & 0.998 \\
\hline women & $497(53.0 \%)$ & $493(52.6 \%)$ & $495(52.8 \%)$ & $493(52.8 \%)$ & $1978(52.8 \%)$ & \\
\hline men & $440(47.0 \%)$ & $444(47.4 \%)$ & $442(47.2 \%)$ & $441(47.2 \%)$ & $1767(47.2 \%)$ & \\
\hline Age group & & & & & & 1.000 \\
\hline below 35 years & $283(30.2 \%)$ & $285(30.4 \%)$ & $284(30.3 \%)$ & $284(30.4 \%)$ & $1136(30.3 \%)$ & \\
\hline 35 - 50 years & $355(37.9 \%)$ & $355(37.9 \%)$ & $355(37.9 \%)$ & $354(37.9 \%)$ & $1419(37.9 \%)$ & \\
\hline over 50 years & $299(31.9 \%)$ & $297(31.7 \%)$ & $298(31.8 \%)$ & $296(31.7 \%)$ & $1190(31.8 \%)$ & \\
\hline Education & & & & & & 0.996 \\
\hline Missing & 3 & 1 & 1 & 2 & 7 & \\
\hline Primary & $293(31.4 \%)$ & $298(31.8 \%)$ & $297(31.7 \%)$ & $293(31.4 \%)$ & $1181(31.6 \%)$ & \\
\hline Higher than primary & $641(68.6 \%)$ & $638(68.2 \%)$ & $639(68.3 \%)$ & $639(68.6 \%)$ & $2557(68.4 \%)$ & \\
\hline Region & & & & & & 1.000 \\
\hline Industrieviertel & $417(44.5 \%)$ & $418(44.6 \%)$ & $420(44.8 \%)$ & $419(44.9 \%)$ & $1674(44.7 \%)$ & \\
\hline Mostviertel & $247(26.4 \%)$ & $244(26.0 \%)$ & $243(25.9 \%)$ & $244(26.1 \%)$ & $978(26.1 \%)$ & \\
\hline Waldviertel & $77(8.2 \%)$ & $81(8.6 \%)$ & $78(8.3 \%)$ & $78(8.4 \%)$ & $314(8.4 \%)$ & \\
\hline Weinviertel & $196(20.9 \%)$ & $194(20.7 \%)$ & $196(20.9 \%)$ & $193(20.7 \%)$ & $779(20.8 \%)$ & \\
\hline Nationality & & & & & & 0.885 \\
\hline Missing & 0 & 2 & 2 & 1 & 5 & \\
\hline Austria & $728(77.7 \%)$ & $737(78.8 \%)$ & $738(78.9 \%)$ & $727(77.9 \%)$ & $2930(78.3 \%)$ & \\
\hline Other nationality & $209(22.3 \%)$ & $198(21.2 \%)$ & $197(21.1 \%)$ & $206(22.1 \%)$ & $810(21.7 \%)$ & \\
\hline Health & & & & & & 0.756 \\
\hline No health restriction & $724(77.3 \%)$ & $733(78.2 \%)$ & $721(76.9 \%)$ & $736(78.8 \%)$ & $2914(77.8 \%)$ & \\
\hline Health restriction & $213(22.7 \%)$ & $204(21.8 \%)$ & $216(23.1 \%)$ & $198(21.2 \%)$ & $831(22.2 \%)$ & \\
\hline Marg. empl. & & & & & & 0.843 \\
\hline No & $837(89.3 \%)$ & $848(90.5 \%)$ & $840(89.6 \%)$ & $836(89.5 \%)$ & $3361(89.7 \%)$ & \\
\hline Yes & $100(10.7 \%)$ & $89(9.5 \%)$ & $97(10.4 \%)$ & $98(10.5 \%)$ & $384(10.3 \%)$ & \\
\hline German & & & & & & 0.411 \\
\hline Partial or non & $143(15.3 \%)$ & $134(14.3 \%)$ & $127(13.6 \%)$ & $151(16.2 \%)$ & $555(14.8 \%)$ & \\
\hline Proficient or native & $794(84.7 \%)$ & $803(85.7 \%)$ & $810(86.4 \%)$ & $783(83.8 \%)$ & $3190(85.2 \%)$ & \\
\hline
\end{tabular}

Table 4: Covariate Balance Chi-squared test Wave 1

We further conducted pairwise z-tests to test for differences in covariates between each of the groups separately, which can be seen in table 5 . Any significant differences would be shown by a letter indicating the group to which the z-test indicated a difference. Again, we can never reject the null hypothesis that there is no difference in the covariates between each of the groups, even when compared pairwise. 


\begin{tabular}{lllll}
\hline & $\mathrm{T} 1(\mathrm{~N}=937)$ & $\mathrm{T} 2(\mathrm{~N}=937)$ & $\mathrm{T} 3(\mathrm{~N}=937)$ & $\mathrm{T} 4(\mathrm{~N}=934)$ \\
& $\mathrm{A}$ & $\mathrm{B}$ & $\mathrm{C}$ & $\mathrm{D}$ \\
\hline Women & 53.0 & 52.6 & 52.8 & 52.8 \\
Men & 47.0 & 47.4 & 47.2 & 47.2 \\
Below 35 years & 30.2 & 30.4 & 30.3 & 30.4 \\
35-50 years & 37.9 & 37.9 & 37.9 & 37.9 \\
Above 50 years & 31.9 & 31.7 & 31.8 & 31.7 \\
Primary education & 31.4 & 31.8 & 31.7 & 31.4 \\
Higher than primary & 68.6 & 68.2 & 68.3 & 68.6 \\
Industriesv. & 44.5 & 44.6 & 44.8 & 44.9 \\
Mostv. & 26.4 & 26.0 & 25.9 & 26.1 \\
Waldv. & 8.2 & 8.6 & 8.3 & 8.4 \\
Weinv. & 20.9 & 20.7 & 20.9 & 20.7 \\
Other nationality & 22.3 & 21.2 & 21.1 & 22.1 \\
Austrian & 77.7 & 78.8 & 78.9 & 77.9 \\
No health restriction & 77.3 & 78.2 & 76.9 & 78.8 \\
Health restriction & 22.7 & 21.8 & 23.1 & 21.2 \\
No marg. empl. & 89.3 & 90.5 & 89.6 & 89.5 \\
Marg. empl. & 10.7 & 9.5 & 10.4 & 10.5 \\
Partial or no German & 15.3 & 14.3 & 13.6 & 16.2 \\
Proficient or native German & 84.7 & 85.7 & 86.4 & 83.8 \\
\hline
\end{tabular}

Table 5: Covariate Balance, pairwise z-tests Wave 1

Second Wave For the second wave, the result of the randomization is as follows. 49 strata were constructed, with a minimum of 13 observations and a maximum of 217, as can be seen in figure 7.

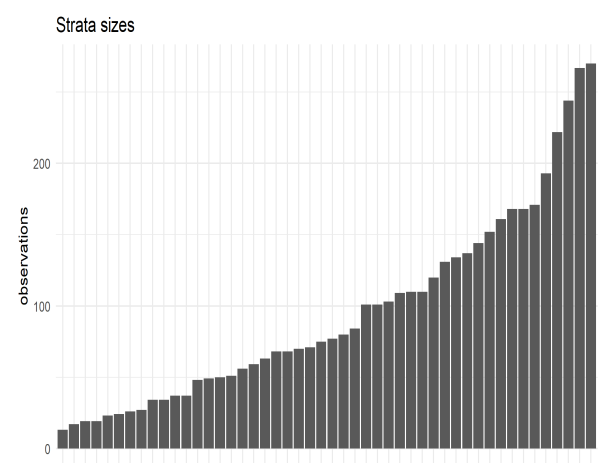

Figure 7: Strata size in Wave 2

Again, we had 20 missing values in education(18) and nationality(2), which were assigned to the groups completely random. Table 6 again shows the results from Chi-squared tests of differences 
between the 4 groups. As in the first wave, the p-values are large, even in those groups where no stratification could be performed.

\begin{tabular}{|c|c|c|c|c|c|c|}
\hline & $\mathrm{T} 1(\mathrm{~N}=1156)$ & $\mathrm{T} 2(\mathrm{~N}=1154)$ & $\mathrm{T} 3(\mathrm{~N}=1152)$ & $\mathrm{T} 4(\mathrm{~N}=1153)$ & Total $(\mathrm{N}=4615)$ & $\mathrm{p}$ value \\
\hline Gender & & & & & & 0.993 \\
\hline women & $594(51.4 \%)$ & $596(51.6 \%)$ & $593(51.5 \%)$ & $599(52.0 \%)$ & $2382(51.6 \%)$ & \\
\hline men & $562(48.6 \%)$ & $558(48.4 \%)$ & $559(48.5 \%)$ & $554(48.0 \%)$ & $2233(48.4 \%)$ & \\
\hline Age group & & & & & & 1.000 \\
\hline below 35 years & $329(28.5 \%)$ & $325(28.2 \%)$ & $326(28.3 \%)$ & $325(28.2 \%)$ & $1305(28.3 \%)$ & \\
\hline $35-50$ years & $441(38.1 \%)$ & $446(38.6 \%)$ & $443(38.5 \%)$ & $445(38.6 \%)$ & $1775(38.5 \%)$ & \\
\hline over 50 years & $386(33.4 \%)$ & $383(33.2 \%)$ & $383(33.2 \%)$ & $383(33.2 \%)$ & $1535(33.3 \%)$ & \\
\hline Education & & & & & & 1.000 \\
\hline Missing & 4 & 5 & 4 & 5 & 18 & \\
\hline Primary & $384(33.3 \%)$ & $382(33.2 \%)$ & $384(33.4 \%)$ & $382(33.3 \%)$ & $1532(33.3 \%)$ & \\
\hline Higher than primary & $768(66.7 \%)$ & $767(66.8 \%)$ & $764(66.6 \%)$ & $766(66.7 \%)$ & $3065(66.7 \%)$ & \\
\hline Region & & & & & & 1.000 \\
\hline Industrieviertel & $516(44.6 \%)$ & $517(44.8 \%)$ & $519(45.1 \%)$ & $516(44.8 \%)$ & $2068(44.8 \%)$ & \\
\hline Mostviertel & $305(26.4 \%)$ & $301(26.1 \%)$ & $303(26.3 \%)$ & $300(26.0 \%)$ & $1209(26.2 \%)$ & \\
\hline Waaldviertel & $89(7.7 \%)$ & $89(7.7 \%)$ & $86(7.5 \%)$ & $90(7.8 \%)$ & $354(7.7 \%)$ & \\
\hline Weinviertel & $246(21.3 \%)$ & $247(21.4 \%)$ & $244(21.2 \%)$ & $247(21.4 \%)$ & $984(21.3 \%)$ & \\
\hline Nationality & & & & & & 0.794 \\
\hline Missing & 1 & 0 & 1 & 0 & 2 & \\
\hline Austria & $912(79.0 \%)$ & $907(78.6 \%)$ & $896(77.8 \%)$ & $917(79.5 \%)$ & $3632(78.7 \%)$ & \\
\hline Other & $243(21.0 \%)$ & $247(21.4 \%)$ & $255(22.2 \%)$ & $236(20.5 \%)$ & $981(21.3 \%)$ & \\
\hline Health & & & & & & 0.985 \\
\hline No health restriction & $904(78.2 \%)$ & $900(78.0 \%)$ & $901(78.2 \%)$ & $895(77.6 \%)$ & $3600(78.0 \%)$ & \\
\hline Health restriction & $252(21.8 \%)$ & $254(22.0 \%)$ & $251(21.8 \%)$ & $258(22.4 \%)$ & $1015(22.0 \%)$ & \\
\hline Marg. empl. & & & & & & 0.734 \\
\hline No & $988(85.5 \%)$ & $1002(86.8 \%)$ & $1001(86.9 \%)$ & $995(86.3 \%)$ & $3986(86.4 \%)$ & \\
\hline Yes & $168(14.5 \%)$ & $152(13.2 \%)$ & $151(13.1 \%)$ & $158(13.7 \%)$ & $629(13.6 \%)$ & \\
\hline German & & & & & & 0.683 \\
\hline Partial or non & $162(14.0 \%)$ & $160(13.9 \%)$ & $148(12.8 \%)$ & $168(14.6 \%)$ & $638(13.8 \%)$ & \\
\hline Proficient or native & $994(86.0 \%)$ & $994(86.1 \%)$ & $1004(87.2 \%)$ & $985(85.4 \%)$ & $3977(86.2 \%)$ & \\
\hline
\end{tabular}

Table 6: Covariate Balance Chi-squared test Wave 2

Finally, table 7 shows the results of the pairwise z-tests, where, again, no differences for any covariate between any groups can be found. 


\begin{tabular}{lllll}
\hline & $\mathrm{T} 1(\mathrm{~N}=1156)$ & $\mathrm{T} 2(\mathrm{~N}=1154)$ & $\mathrm{T} 3(\mathrm{~N}=1152)$ & $\mathrm{T} 4(\mathrm{~N}=1153)$ \\
& $\mathrm{A}$ & $\mathrm{B}$ & $\mathrm{C}$ & $\mathrm{D}$ \\
\hline Women & 51.4 & 51.6 & 51.5 & 52.0 \\
Men & 48.6 & 48.4 & 48.5 & 48.0 \\
Below 35 years & 28.5 & 28.2 & 28.3 & 28.2 \\
35-50 years & 38.1 & 38.6 & 38.5 & 38.6 \\
Above 50 years & 33.4 & 33.2 & 33.2 & 33.2 \\
Primary education & 33.3 & 33.2 & 33.4 & 33.3 \\
Higher than primary & 66.7 & 66.8 & 66.6 & 66.7 \\
Industriev. & 44.6 & 44.8 & 45.1 & 44.8 \\
Mostv. & 26.4 & 26.1 & 26.3 & 26.0 \\
Waldv. & 7.7 & 7.7 & 7.5 & 7.8 \\
Weinv. & 21.3 & 21.4 & 21.2 & 21.4 \\
Other nationality & 21.0 & 21.4 & 22.2 & 20.5 \\
Austrian & 79.0 & 78.6 & 77.8 & 79.5 \\
No health restriction & 78.2 & 78.0 & 78.2 & 77.6 \\
Health restriction & 21.8 & 22.0 & 21.8 & 22.4 \\
No marg. empl. & 85.5 & 86.8 & 86.9 & 86.3 \\
Marg. empl. & 14.5 & 13.2 & 13.1 & 13.7 \\
Partial or no German & 14.0 & 13.9 & 12.8 & 14.6 \\
Proficient or no German & 86.0 & 86.1 & 87.2 & 85.4 \\
\hline
\end{tabular}

Table 7: Covariate Balance, pairwise z-tests Wave 2

Third Wave For the third wave, the result of the randomization is as follows. 49 strata were constructed, with a minimum of 11 observations and a maximum of 160, as can be seen in figure 8 .

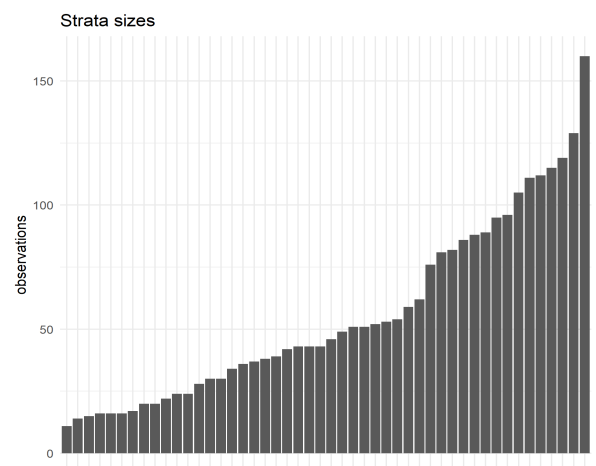

Figure 8: Strata size in Wave 3

Again, we had 11 missing values in education), which were assigned to the groups completely random. Table 8 shows the results from Chi-squared tests of differences between the 4 groups. As 
in the other waves, the p-values are large, even in those groups where no stratification could be performed.

\begin{tabular}{|c|c|c|c|c|c|c|}
\hline & $\mathrm{T} 1(\mathrm{~N}=676)$ & $\mathrm{T} 2(\mathrm{~N}=675)$ & T3 $(\mathrm{N}=671)$ & $\mathrm{T} 4(\mathrm{~N}=668)$ & Total $(\mathrm{N}=2690)$ & $\mathrm{p}$ value \\
\hline Gender & & & & & & 1.000 \\
\hline women & $346(51.2 \%)$ & $345(51.1 \%)$ & $345(51.4 \%)$ & $342(51.2 \%)$ & $1378(51.2 \%)$ & \\
\hline men & $330(48.8 \%)$ & $330(48.9 \%)$ & $326(48.6 \%)$ & $326(48.8 \%)$ & $1312(48.8 \%)$ & \\
\hline Age group & & & & & & 1.000 \\
\hline below 35 years & $219(32.4 \%)$ & $218(32.3 \%)$ & $216(32.2 \%)$ & $214(32.0 \%)$ & $867(32.2 \%)$ & \\
\hline 35 - 50 years & $266(39.3 \%)$ & $266(39.4 \%)$ & $266(39.6 \%)$ & $264(39.5 \%)$ & $1062(39.5 \%)$ & \\
\hline over 50 years & $191(28.3 \%)$ & $191(28.3 \%)$ & $189(28.2 \%)$ & $190(28.4 \%)$ & $761(28.3 \%)$ & \\
\hline Education & & & & & & 0.998 \\
\hline Missing & 3 & 3 & 3 & 2 & 11 & \\
\hline Primary & $220(32.7 \%)$ & $218(32.4 \%)$ & $215(32.2 \%)$ & $216(32.4 \%)$ & $869(32.4 \%)$ & \\
\hline Higher than primary & $453(67.3 \%)$ & $454(67.6 \%)$ & $453(67.8 \%)$ & $450(67.6 \%)$ & $1810(67.6 \%)$ & \\
\hline Region & & & & & & 1.000 \\
\hline Industrieviertel & $289(42.8 \%)$ & $290(43.0 \%)$ & $288(42.9 \%)$ & $284(42.5 \%)$ & $1151(42.8 \%)$ & \\
\hline Mostviertel & $189(28.0 \%)$ & $186(27.6 \%)$ & $186(27.7 \%)$ & $188(28.1 \%)$ & $749(27.8 \%)$ & \\
\hline Waldviertel & $77(11.4 \%)$ & $75(11.1 \%)$ & $75(11.2 \%)$ & $73(10.9 \%)$ & $300(11.2 \%)$ & \\
\hline Weinviertel & $121(17.9 \%)$ & $124(18.4 \%)$ & $122(18.2 \%)$ & $123(18.4 \%)$ & $490(18.2 \%)$ & \\
\hline Nationality & & & & & & 0.375 \\
\hline Austria & $507(75.0 \%)$ & $502(74.4 \%)$ & $516(76.9 \%)$ & $521(78.0 \%)$ & $2046(76.1 \%)$ & \\
\hline Other & $169(25.0 \%)$ & $173(25.6 \%)$ & $155(23.1 \%)$ & $147(22.0 \%)$ & $644(23.9 \%)$ & \\
\hline Health & & & & & & 0.801 \\
\hline No health restriction & $557(82.4 \%)$ & $544(80.6 \%)$ & $546(81.4 \%)$ & $538(80.5 \%)$ & $2185(81.2 \%)$ & \\
\hline Health restriction & $119(17.6 \%)$ & $131(19.4 \%)$ & $125(18.6 \%)$ & $130(19.5 \%)$ & $505(18.8 \%)$ & \\
\hline Marg. empl. & & & & & & 0.693 \\
\hline No & $632(93.5 \%)$ & $629(93.2 \%)$ & $626(93.3 \%)$ & $632(94.6 \%)$ & $2519(93.6 \%)$ & \\
\hline Yes & $44(6.5 \%)$ & $46(6.8 \%)$ & $45(6.7 \%)$ & $36(5.4 \%)$ & $171(6.4 \%)$ & \\
\hline German & & & & & & 0.872 \\
\hline Partial or non & $99(14.6 \%)$ & $109(16.1 \%)$ & $102(15.2 \%)$ & $99(14.8 \%)$ & $409(15.2 \%)$ & \\
\hline Proficient or native & $577(85.4 \%)$ & $566(83.9 \%)$ & $569(84.8 \%)$ & $569(85.2 \%)$ & $2281(84.8 \%)$ & \\
\hline
\end{tabular}

Table 8: Covariate Balance Chi-squared test Wave 3

Finally, table 7 shows the results of the pairwise z-tests, where, again, no differences for any covariate between any groups can be found. 


\begin{tabular}{lllll}
\hline & $\mathrm{T} 1(\mathrm{~N}=676)$ & $\mathrm{T} 2(\mathrm{~N}=675)$ & $\mathrm{T} 3(\mathrm{~N}=671)$ & $\mathrm{T} 4(\mathrm{~N}=668)$ \\
& $\mathrm{A}$ & $\mathrm{B}$ & $\mathrm{C}$ & $\mathrm{D}$ \\
\hline Women & 51.9 & 51.8 & 51.9 & 52.1 \\
Men & 48.1 & 48.2 & 48.1 & 47.9 \\
& & & & \\
Below 35 years & 30.0 & 29.9 & 29.9 & 29.9 \\
35-50 years & 38.4 & 38.6 & 38.6 & 38.6 \\
Above 50 years & 31.6 & 31.5 & 31.5 & 31.5 \\
Primary education & 32.5 & 32.6 & 32.6 & 32.4 \\
Higher than primary & 67.5 & 67.4 & 67.4 & 67.6 \\
Industriev. & 44.1 & 44.3 & 44.5 & 44.2 \\
Mostv. & 26.8 & 26.4 & 26.5 & 26.6 \\
Waldv. & 8.8 & 8.9 & 8.7 & 8.7 \\
Weinv. & 20.3 & 20.4 & 20.4 & 20.4 \\
Other nationality & 22.4 & 22.4 & 22.0 & 21.4 \\
Austrian & 77.6 & 77.6 & 78.0 & 78.6 \\
No health restriction & 78.9 & 78.7 & 78.6 & 78.7 \\
Health restriction & 21.1 & 21.3 & 21.4 & 21.3 \\
No marg. empl. & 88.7 & 89.6 & 89.4 & 89.4 \\
Marg. empl. & 11.3 & 10.4 & 10.6 & 10.6 \\
Partial or no German & 14.6 & 14.6 & 13.7 & 15.2 \\
Proficient or no German & 85.4 & 85.4 & 86.3 & 84.8 \\
\hline
\end{tabular}

Table 9: Covariate Balance, pairwise z-tests Wave 3 